\title{
2-(2-chlorophenyl)-1H-Benzimidazole as a New Corrosion Inhibitor for Copper in Sulfuric Acid
}

\author{
Jinliang Zhang ${ }^{1, *}, \mathrm{Hao} \mathrm{Li}^{2}$ \\ ${ }^{1}$ School of Materials and Chemical Engineering, Ningbo University of Technology, Ningbo \\ Zhejiang 315211, China \\ ${ }^{2}$ School of Chemistry and Chemical Engineering, Chongqing University, Chongqing, 400044, \\ China \\ *E-mail: zhangjinliang_nut@126.com
}

doi: $10.20964 / 2020.06 .63$

Received: 11 January 2020 / Accepted: 10 March 2020 / Published: 10 May 2020

\begin{abstract}
A benzimidazole derivative namely 2-(2-chlorophenyl)-1H-Benzimidazole (CPBI) was investigated for corrosion inhibition of copper in $0.5 \mathrm{~mol} \mathrm{~L}^{-1} \mathrm{H}_{2} \mathrm{SO}_{4}$ solution using electrochemical methods, scanning electron microscope (SEM), and laser scanning confocal microscope (LSCM). We found that the adsorption of CPBI molecules on copper conforms to a Langmuir type adsorption isotherm and belongs to a mixed type inhibitor. With the addition of $5 \mathrm{mmol} \mathrm{L}^{-1} \mathrm{CPBI}$, the maximum efficiencies of $92.3 \%$ was obtained, whereas $5 \mathrm{mmol} \mathrm{L}^{-1}$ benzimidazole (BIM) only have $70.1 \%$ ability. The topography maps of SEM and LSCM are consistent with the electrochemical results. In addition, molecular dynamics simulation and quantum chemical calculation further reveal the adsorption and inhibition mechanism of CPBI from a microscopic level.
\end{abstract}

Keywords: Corrosion inhibition, Copper, acid, Langmuir isotherm, MD

\section{FULL TEXT}

(C) 2020 The Authors. Published by ESG (www.electrochemsci.org). This article is an open access article distributed under the terms and conditions of the Creative Commons Attribution license (http://creativecommons.org/licenses/by/4.0/). 